\title{
O MÉTODO QUALITATIVO NORTEANDO A PESQUISA SOCIAL
}

\author{
F.CARLOS, W.O.R. TEIXEIRA, K.OLIVEIRA, K. QUEIROZ \\ Instituto Federal de Educação, Ciência e Tecnologia do Rio Grande do Norte \\ walkyria.teixeira@ifrn.edu.br
}

O livro Pesquisa Social - teoria, método e criatividade, organizado pela socióloga, antropóloga e sanitarista Maria Cecília de Souza Minayo tem contribuições de Romeu Gomes, psicólogo e mestre em psicopedagogia, de Suely Ferreira Deslandes, socióloga e mestre em saúde pública, e de Otávio Cruz Neto, sociólogo e mestre em educação, os quais juntos produziram o pertinente trabalho no intuito de familiarizar os interessados em pesquisas no campo das ciências sociais com os elementos primordiais de um projeto científico ligado a referida seara.

A obra foi lançada em 1994, hoje 21 anos depois, está em sua 34ạ edição trazendo consigo informações preciosas que auxiliarão no alcance do grau de formalidade indispensável ao trabalho científico sem abrir mão da criatividade do pesquisador. No referido lapso temporal, os autores do livro aprimoraram seu conteúdo, mormente no tocante aos métodos e regras para a produção científica, corroborando a ideia de mutação correlata a pesquisa social.

O livro é composto por quatro capítulos, os quais introduzem o leitor aos preceitos inerentes à investigação social. De maneira simples e didática, aspectos teóricos e práticos vão sendo externados de forma transparente e concatenada. Na primeira parte da obra, observa-se um caráter mais teórico trazendo à baila questões polêmicas do mundo científico, ao passo que a segunda parte enfatiza o lado mais técnico, ligado às ações mais pragmáticas, presentes na execução do estudo.

Assim, no capítulo 1, intitulado "O desafio da pesquisa social" de autoria de Maria Cecília de Souza Minayo, são introduzidas questões teóricas contidas no âmago da pesquisa social, tais como a definição de ciência, a distinção entre ciências humanas e ciências sociais de ciências naturais, ou ainda o próprio conceito de pesquisa e seu tratamento no âmbito científico. Seu conteúdo instiga a busca por uma concepção de ciência pautada numa ideia de complementação, pois adverte ao leitor que o campo científico não possui exclusividade na decodificação da realidade.

Neste capítulo 1 é desenvolvida a questão da cientificidade presente na pesquisa social, enaltecendo seu caráter regulador de alta abstração diversamente de modelos e normas impostas. 
Já a metodologia é abordada como sendo o encadeamento lógico do pensamento durante a análise empreendida. Está associada às teorias que subsidiarão o trabalho, fornecendo explicações e auxiliando na junção dos dados adquiridos na pesquisa a fim de iluminar os resultados.

A abordagem qualitativa também é destacada por Minayo que direciona seus esforços na leitura de aspectos que alcançam ações humanas, bem como os significados imbricados no objeto de análise. Diversamente do experimentado no método quantitativo.

O ciclo da pesquisa finaliza esse primeiro capítulo, sendo apresentado como o procedimento que liga cada etapa da confecção do estudo, numa sequência lógica e progressiva culminando com a produção do conhecimento afirmativo.

No capítulo 2 , intitulado "O projeto de pesquisa como exercício científico e artesanato intelectual", de autoria da Professora Suely Ferreira Deslandes é proposta a reflexão de como o projeto de pesquisa é construído. Para ela é como um artefato elaborado por meio do trabalho intelectual com o domínio das teorias e métodos e do trabalho investigativo realizado pelo investigador. $\mathrm{O}$ projeto de pesquisa pode ser considerado o caminho para abordar a realidade, visando trabalhar com o objeto construído e não com o objeto percebido ou real. A autora apresenta as três dimensões necessárias para a etapa da reconstrução do objeto, sendo este momento no qual se define o objeto e como investigá-lo, sendo elas: técnica, que trata das regras científicas; a ideológica que está relacionada as próprias escolhas do pesquisador, momento que será definido o que pesquisar, qual a base teórica a ser abordada e como pesquisar; e por fim a científica, momento que será articulada as dimensões supracitadas a fim de que a pesquisa ultrapasse o senso comum por meio do método científico.

No tocante ao propósito do projeto de pesquisa, este tem como finalidade esclarecer a questão investigada para o pesquisador, as definições teóricas e as estratégias do estudo, e ainda o que precisa ampliar, definir e refletir para concluí-lo. É enfatizada a importância de a pesquisa ser informada à academia a fim de que seja aceita na comunidade científica, e diz que o projeto também serve de fonte para se obter financiamento junto às instituições de fomento à pesquisa.

Na fase exploratória, considerada pela autora o momento mais importante da pesquisa, tem-se as várias fases da construção da investigação: escolha do tópico de investigação; delimitação do objeto; definição dos objetivos; construção do marco teórico conceitual; seleção dos instrumentos de construção/coleta de dados; e exploração do campo. Para a autora é a partir daí que o projeto de pesquisa deve responder a algumas questões que passam a constituir os elementos 
do projeto, são elas: o que pesquisar? Para quê pesquisar? Por que pesquisar? Como pesquisar? Por quanto tempo pesquisar? Com que recursos? A partir de quais fontes?

A autora destaca também algumas questões relativas à ética do pesquisador no decorrer da elaboração do projeto de pesquisa, como: não ferir a ética na elaboração de textos científicos, agindo com comportamentos antiéticos como o de plagiar a ideia de outros autores sem autorização; fraudar dados para fundamentar sua pesquisa; ter a preocupação em não causar danos aos sujeitos envolvidos na pesquisa. Assim, ressalta que, tem área do conhecimento, como saúde, que o projeto deve ser submetido ao comitê de ética em pesquisa.

Nesse capítulo, a autora apresenta como um projeto de pesquisa deve ser organizado, de acordo com os seus elementos essenciais com fundamento nas regras da ABNT, quais sejam: a) prétextuais (Capa; Página de rosto; Sumário; Lista de ilustrações - gráficos, tabelas e quadros; Lista de símbolos e abreviaturas - opcional; b) Elementos textuais (Apresentação do tema e do problema; Hipótese; Objetivos; Justificativas; Quadro teórico; Metodologia e Orçamento; e c) Elementos póstextuais (Referências bibliográficas e Anexos e apêndices - opcional). (DESLANDES, 2015, p. 56).

O capítulo 3, denominado "Trabalho de campo: contextos de observação, interação e descoberta" é também de autoria de Minayo que traz algumas reflexões acerca do trabalho de campo na pesquisa social. Para ela é nessa etapa da pesquisa que é permitido ao pesquisador ter um contato mais próximo com a realidade estudada, bem como interagir com os personagens nela envolvidos. Esse trabalho pode ser desenvolvido, entre outras técnicas, através da entrevista ou observação participante, que segundo a autora, se configuram como as principais para a pesquisa social.

Para a autora, a entrevista pode ser considerada uma conversa com finalidade. Sua caracterização é definida por sua forma de organização, seja sondagem de opinião, semiestruturada, abertas, focalizadas, projetiva, narrativas de vida ou grupo focal;em qualquer destas possibilidades, a fala é o material primordial. A técnica da entrevista enquanto forma privilegiada de interação social está sujeita à dinâmica das relações existentes na sociedade. Assim sendo, para a análise desta, se faz necessário contextualizá-la e quando possível somar a ela o uso da observação participante.

Quanto à observação participante, a autora caracteriza-a como técnica em que o pesquisador se insere em determinada realidade social com o objetivo de desenvolver uma pesquisa científica, sendo partícipe daquele contexto. Logo, tanto o pesquisador altera esse mesmo contexto, 
como também sofre alterações. A observação participante fundamenta-se na condição de relativizar o espaço social, tendo a oportunidade de se perceber no lugar do outro.

Segundo Minayo, no campo de pesquisa social tudo necessita ser compreendido como fenômeno social e historicamente condicionado, tais como: o objeto investigado, pessoas implicadas na atividade, pesquisador e seu sistema de representações teórico-ideológicas, técnicas de pesquisa e o conjunto de relações interpessoais e de comunicação simbólica.

Minayo ainda ensina que nossa capacidade de análise é exercitada quando conseguimos estabelecer um diálogo entre o material colhido no campo e os pressupostos estabelecidos para a pesquisa. Porém, faz-se necessário lembrar que o próprio processo de trabalho de campo pode também nos conduzir a reformular ou redimensionar nossas hipóteses e caminhos de pesquisa.

No capítulo 4, de autoria de Romeu Gomes intitulado como "Análise e interpretação de dados de pesquisa qualitativa" são mencionadas observações relevantes para o pesquisador como: o conjunto de opiniões e representações sociais sobre o objeto de estudo, tendo atenção para a homogeneidade e heterogeneidade na sociedade; o conceito de análise e interpretação que consiste em ir além da descrição; a interpretação com o objetivo de entender e dar sentido ao que foi descrito e analisado.É importante ressaltatar antes da introdução acerca da compreensão da análise de conteúdo que é uma técnica tradicional que surgiu na pesquisa quantitativa e atualmente é incoporada na qualititativa. Gomes (2015) fundamenta-se em Bardin (1979) e Minayo (2006) para apresentar o leitor referências sobre essa temática.

Segundo Gomes, a análise de conteúdo teve origem no século $\mathrm{XX}$, em que prevalecia o behaviorismo corrente psicológica marcada pela rigorosidade e cientificidade, como também pela narração de comportamentos, podendo ser aplicada em várias situações como obras de romance e depoimentos.

Dentre as técnicas de análise do material da pesquisa é destacado por Gomes a avaliação ou representacional baseada na medição das ações do locutor quanto à sua fala; de expressão que se fundamenta no tipo de discurso, o locutor e o lugar em que ele se insere levando em conta suas singularidades; a anunciação utilizada em entrevistas abertas pautada na comunicação e temática que denota representar o assunto principal. Nesse processo é importante considerar que as unidades de registro são os elementos que foram separados do conteúdo e as unidades de contexto referem-se ao entendimento da conjuntura da mensagem. 
Na pesquisa qualitativa, segundo Gomes (2015), a partir do que foi explanado acerca da análise de conteúdo é importante assinalar os procedimentos metodológicos que são: a categorização que requer do pesquisador organizar a classificação do tema a ser analisado; a inferência como conclusão coerente do conteúdo; a descrição que dará caráter ao texto; e a interpretação, que segundo Minayo (2006) remete à relação existente entre as estruturas semânticas com as sociológicas apresentadas na mensagem.

Quanto à trajetória de análise de conteúdo temática, segundo Gomes (2015) c consiste em três etapas. A primeira concernente à leitura do material da pesquisa com o intuito de compreendêlo. A segunda refere-se à exploração do material, caracterizando a análise em si a partir da distribuição dos trechos do texto, da leitura, identificação das inferências e dos núcleos de sentidos. E a última, remete à redação que expressa o diálogo com o tema, objetivos e questões da pesquisa como forma de síntese.

É apresentado ainda no capítulo 4 o exemplo de análise e interpretação de conteúdo com uma suposta pesquisa sobre a "representação feminista do uso do preservativo" (p. 92), com o objetivo de analisar como as mulheres de classes populares se expressam quanto ao assunto. Este tinha como fundamentação teórica as concepções de Gramsci. As exemplificações visam à assimilação acerca das características da análise de conteúdo temática que foram explanados pelos autores no decorrer do livro, quais sejam: categorização, núcleos de sentido, inferência e a redação da pesquisa.

Este livro buscou sistematizar os principais passos na construção do conhecimento, mediante a elaboração do projeto e da condução da pesquisa social. Neste trabalho, é apresentado o caminho para abordar a realidade na produção do objeto científico, com fundamento nas teorias, no método e na criatividade do pesquisador.

Durante a exposição, o leitor é instigado a perceber as diferenças entre a pesquisa qualitativa e a quantitativa, pois é preciso que o pesquisador enxergue as peculiaridades inerentes aos fenômenos sociais, assim como as influências advindas das diversas áreas do conhecimento e que repercutem no objeto de estudo.

Assim, os autores defendem a configuração da cientificidade aplicada à pesquisa social. Em que pese existir distinções entre a pesquisa social e as ciências naturais. Na pesquisa social a cientificidade caminha observando enfoques específicos, haja vista a abordagem qualitativa 
direcionar seus esforços para a leitura de aspectos que alcancem ações humanas, bem como os significados imbricados ao objeto de análise.

Note que o trabalho consegue conjugar aspectos teóricos e práticos que auxiliarão o pesquisador no desenvolvimento de todo o trajeto de estudo a fim de obter o produto final de sua pesquisa. A riqueza de detalhes, ofertados no percusso da leitura, contribuiram sobremaneira para entendermos a sequência lógica a ser enfrentada durante o processo árduo de análises, confrontações de teorias, aplicação de técnicas e utilização da criatividade do estudioso na confecção das pesquisas.

Trata-se de uma obra indispensável para aqueles que se aventuram nos caminhos da produção do conhecimento, pois nela são desvelados os passos necessários para a construção de pesquisas comprometidas com o rigor que a academia exige, sem deixar de demonstrar o itinerário a ser percorrido de maneira clara e objetiva.

Logo, para aqueles que se propõem a enfrentamento dos obstáculos inerentes a produção do conhecimento, mostra-se imperiosa a leitura deste livro haja vista ele configurar-se numa obra basilar capaz de iluminar as principais inquietações presentes nas pequisas sociais.

Caro leitor, vale à pena enriquecer seu horizonte por meio dos capítulos contidos nessa obra, os quais certamente contribuirão para o processo artezanal de criação e estruturação da pesquisa social e na sua trajetória para elaboração de um projeto de pesquisa.

\section{REFERÊNCIA}

MINAYO, M. C. S. (Org.); DESLANDES, S.F.; CRUZ NETO, O. GOMES. R. Pesquisa Social: teoria, método e criatividade. 34. Ed. Petrópolis, RJ: Vozes, 2015. 